\title{
An assessment of agility in selected hospitals of Mazandaran province, Iran
}

\section{Ghahraman Mahmoudi $^{1^{*}}$, Masoomeh Abdi Talarposhti ${ }^{2}$}

1. Research Center of Hospital Administration, Faculty of Medicine, Sari Branch, Islamic Azad University, Sari, Iran

2. Department of Health Services Management, Sari Branch, Islamic Azad University, Sari, Iran

*Corresponding author:Tel: +98 9111545461 Fax: +98 15133033858

Address: Research Center of Hospital Adminstration, Medical School, Islamic Azad University, Sari Branch, Sari, Mazandran.

E-mail:ghahraman48@yahoo.com

Received: 2018/(02/20 revised: 2018/04/11 accented: 2018/04/26

\section{Abstract}

Introduction: Evaluating agility effectively and efficiently is necessary and challenging for organizations. Therefore, this article aimed to assess the performance of hospitals with organizational agility (OA) approach.

Materials and methods: A descriptive-analytical study was done in which the statistical population consisted of managers and experts of hospital courses including medicine, nursing, midwifery, and paramedics. A total of 283 managers and experts were enrolled as the sample using the Krejcie and Morgan table with stratified random sampling. Data were analyzed using one-sample t test with SPSS20.

Results: Among 13 elements of agility, the results showed that competence $(\mathrm{P}=0.032)$ had a significant difference with customer satisfaction $(\mathrm{P}=0.029)$. The results also showed that $\mathrm{OA}$ was not optimal in selected hospitals of Mazandaran province, Iran. Concerning the indicators, introduction of new product (8.56) and staff skill development indicator (5.32) were maximum and minimum, respectively.

Conclusion: The results showed that OA was not optimal in selected hospitals. Introduction of new product scored the top, while staff skill development was the lowest. As a result, health policy makers are recommended to plan for customer satisfaction, timely utilization of facilities, elimination of weak points, lost cost reduction, encouragement and punishment system for staff, and staff empowerment.

Keywords: Organizational agility, Accountability, Competence, Flexibility, Speed, Hospital

\section{Introduction}

The simultaneous advancements of Preparation Management and Nimbleness have resulted in the concepts of nimble chain. Nimbleness is perceived not only as the chain range strategy (1) but also as a paradigm for engineering the competitive organizations and institutions (2). Today, the organizations work in the competitive and dynamic settings that are encountered with various challenges (3). Nimbleness is a response to the imposed challenges from business setting which is encompassed with change and uncertainty (4). The nimble organizations should not only be responsive to the occurred changes but also they have to be able to gain the competitive advantages through appropriate arrangements (5). In such circumstances, the smallest errors can result in organization decline (6). Among the

Copyright (C) 2018 Journal of Basic Research in Medical Science. This is an open access article distributed under the terms of the Creative Commons Attribution 4.0 International License (https://creativecommons.org/licenses/by/4.0/) which permits copy and redistribute the material, in any medium or format, provided the original work is properly cited. 
features of agile organizations is the ability to respond to changes and sudden events. With the help of these tools, it is possible to detect attacks of environmental, infectious, contagious, and even bioterroristic diseases at local, regional and national levels; and then, make the organizations prepared to respond to them (7). To provide quality cares with reduced costs, agile health care organizations can detect misconducts and frauds, by identifying the relationship between the diagnosis and the conducted tests, number of consultations and length of stays, as well as the matching of costs with the treatments, and achieve the highest possible efficiency and lowest costs of treatments (8). Besides, decreasing the production costs; increasing the customer's satisfaction; removing the activities without added value; and increasing the competition are among the advantages which can be gained through the nimbleness strategy (9). The health system isn't exception to this fact and without change, the management of the health system will not be able to make changes in this organization according to what the goals of the health policies requires (10). Today, the hospitals as the biggest and the most expensive operational unit of the health system, are so important and particularly sensitive in the medical and hygiene economic (11); and they are of the most complex organizations during the mankind history which are hard to manage (12). Charlene offered a method to assess the nimbleness rate in which two measures of ability to response to changes and invisible nimbleness infrastructure were applied (13). The problems of Health systems and hospitals are as much that people can't tolerate any more problems. According to the officials, these patients receive 80 percents of their hospitalization services from the state hospitals. This fact is not something secret, and service providers in these centers should respect the patients' dignity (14). Due to the complexity, diversity and frequency of activities, techniques and tools such as data mining (knowledge extraction from the knowledge base) and text mining (automatic extraction of new and unknown information from written sources) are required in order to transforms these data into useful information and knowledge (15). With the help of text mining, Don Swanson sought to find some hypotheses for the cause of rare diseases (16). He also used the data mining technique in the Bals Infectious Diseases Institute to manage AIDS (17). The nimbleness assessment, which is applied as a process revealing the indices and indicators in different working fields and areas, significantly helps policymaking and is an important factor for monitoring and controlling the systems (18). In the other words, to survive, today's organizations have to be nimble and dynamic and their managers and staffs should be creative and innovative in order to be able to conform their organization to the changes and response to the society and customers' needs (19). Regarding the what was said before, each organization should arrange itself nimbly to response to a set of internal and external forces; thus, to gain the consistent achievements, the organization should provide a level of nimbleness to adapt themselves with the increase in the level of changes and complexity; So, this study has been conducted to assess the hospitals' Agility rate in Mazandaran Province.

\section{Materials and methods}

This is an applied, descriptive-analytical study, conducted in 2015. A total of 328 managers and experts were enrolled as the sample using the Krejcie \& Morgan table with stratified random sampling. The study was carried out in Mazandaran hospitals province, Iran. Two central hospitals, two western hospitals, and two eastern hospitals were randomly selected in Mazandaran province using clustering sampling. Considering the allocated sample to each hospital, stratified sampling was employed in each hospital. Data were collected using a two-section questionnaire. The first section was dedicated to demographic 
characteristics (age, gender, level of education, work experience, course of study). The second section was designed for public hospital agility. A 53-item OA Questionnaire was employed for assessing agility (competence, accountability, flexibility, and speed of delivery) and 11 factors including Staff Skills, Information Technology Application, Integration of Processes, Sensitivity and Accountability to Market, Proper Planning, Introduction of New Product, Cost Reduction, Customer Satisfaction, Product Quality. The items were scored on a 5-option Likert scale (Strongly Agree, Agree, Neutral, Disagree, and Strongly Disagree). The validity of the research was calculated to be equal to $97 \%$ for all questions, based on the content validity and reliability of the questionnaire and the method of Cronbach's alpha, used in a research carried out by Abdi in 2014, entitled "Designing a Model for Agility of Public Hospitals in Iran". Since the Cronbach's alpha value is greater than $7 \%$, it can be claimed that the test has an acceptable reliability. The questionnaires were forwarded after ensuring the confidentiality and obtaining the permits.
The researcher clarified the questions in case of need. The inclusion criteria were bachelor degree in health centers courses, written consent, and observation of confidentiality. Finally, the data were analyzed using descriptive statistics (mean, standard deviation, frequency, frequency percentage) and inferential statistics (onesample $t$ test and t-independent test) using SPSS 20.

\section{Results}

According to the findings, $55 \%$ of the participants were female and $44 \%$ were male. $36 \%$ of the participants were aged 3640 and only $1 \%$ of the participants were older than 50. Age distribution curve is skewed heavily on the younger age groups. $47 \%$ of the participants had bachelor degree (the greatest frequency) and 6\% were Ph.D and specialist (the lowest frequency). 38\% of the participants had 6-10 years of work experience and $1 \%$ of the participants had more than 26 years of work experience. Work experience curve is skewed heavily on lower work experience groups (Table 1).

Table 1. Distribution and frequency of demographic features in the hospitals of Mazandaran province, in 2015.

\begin{tabular}{llc}
\hline Variable & & Frequency (Percentage) \\
\hline Gender & Female & $179(55)$ \\
& Unale & $145(44)$ \\
& $<30$ & $4(1)$ \\
& $31-35$ & $26(8)$ \\
& $36-40$ & $82(25)$ \\
& $41-45$ & $117(36)$ \\
Education level & $46-50$ & $58(18)$ \\
& $>51$ & $27(8)$ \\
& Unanswered & $17(6)$ \\
& Bachelor Degree & $1(0.3)$ \\
& Master Degree & $154(47)$ \\
& General physician & $62(18)$ \\
Work experience (year) & Doctor of Philosophy & $61(18)$ \\
& Expert physician & $18(6)$ \\
& Unanswered & $18(6)$ \\
& $<5$ & $15(4)$ \\
& $6-10$ & $34(5)$ \\
& $11-15$ & $123(38)$ \\
& $16-20$ & $120(37)$ \\
& $21-25$ & $40(12)$ \\
& $>26$ & $8(2)$ \\
& & $3(1)$ \\
\hline
\end{tabular}


Since the mean score of OA questionnaire ranges between 1 and 5 , the theoretical mean is 3 . As shown in table 2 , the mean score of OA is lower than 3 (1.57), showing the fact that OA was not optimal in selected hospitals. Since the research variables were not normal, non-parametric tests were used.

Table 2. Description of the organizational agility indices in selected hospitals of Mazandaran province.

\begin{tabular}{lc}
\hline Variable & Mean \pm standard deviation \\
\hline Competence & $1.53 \pm 0.51$ \\
Accountability & $1.53 \pm 0.53$ \\
Flexibility & $1.56 \pm 0.64$ \\
Speed of Delivery & $1.55 \pm 0.76$ \\
Staff Skill Development & $1.33 \pm 0.46$ \\
IT Application & $1.56 \pm 0.52$ \\
Integration of Processes & $1.52 \pm 0.52$ \\
Sensitivity and Accountability to & $1.70 \pm 0.70$ \\
Market & $1.57 \pm 0.65$ \\
Proper Planning & $1.77 \pm 0.56$ \\
Introduction of New Products & $1.58 \pm 0.60$ \\
Reduced Costs & $1.53 \pm 0.57$ \\
Customer Satisfaction & $1.59 \pm 0.69$ \\
Product Quality & $1.57 \pm 0.37$ \\
Organizational Agility &
\end{tabular}

Table 3. Results of binominal test for comparing the opinions of subjects concerning organizational agility.

\begin{tabular}{|c|c|c|c|c|}
\hline Variable & Number & Observation ratio & Expected probability & P value \\
\hline \multirow{2}{*}{ Hospital competence } & $324 *$ & $99 \%$ & 0.05 & 0.0001 \\
\hline & $4 * *$ & $1 \%$ & 0.05 & 0.0001 \\
\hline \multirow[t]{2}{*}{ Hospital accountability } & $322 *$ & $98 \%$ & 0.05 & 0.0001 \\
\hline & $6^{* *}$ & $2 \%$ & 0.05 & 0.0001 \\
\hline \multirow{2}{*}{ Hospital flexibility } & $313 *$ & $96 \%$ & 0.05 & 0.0001 \\
\hline & $14 * *$ & $4 \%$ & 0.05 & 0.0001 \\
\hline \multirow[t]{2}{*}{ Hospital speed of delivery } & $310^{*}$ & $95 \%$ & 0.05 & 0.0001 \\
\hline & $17 * *$ & $5 \%$ & 0.05 & 0.0001 \\
\hline \multirow[t]{2}{*}{ Staff skill development } & $310^{*}$ & $95 \%$ & 0.05 & 0.0001 \\
\hline & $17 * *$ & $5 \%$ & 0.05 & 0.0001 \\
\hline \multirow[t]{2}{*}{ IT application } & $326^{*}$ & $99 \%$ & 0.05 & 0.0001 \\
\hline & $1 * *$ & $1 \%$ & 0.05 & 0.0001 \\
\hline \multirow[t]{2}{*}{ Integration of processes } & $325^{*}$ & $99 \%$ & 0.05 & 0.0001 \\
\hline & $2 * *$ & $1 \%$ & 0.05 & 0.0001 \\
\hline \multirow[t]{2}{*}{ Sensitivity and accountability to market } & $317 *$ & $97 \%$ & 0.05 & 0.0001 \\
\hline & $9 * *$ & $3 \%$ & 0.05 & 0.0001 \\
\hline \multirow[t]{2}{*}{ Proper planning } & $319^{*}$ & $98 \%$ & 0.05 & 0.0001 \\
\hline & $7 * *$ & $2 \%$ & 0.05 & 0.0001 \\
\hline \multirow[t]{2}{*}{ Introduction of new products } & $319^{*}$ & $98 \%$ & 0.05 & 0.0001 \\
\hline & $7 * *$ & $2 \%$ & 0.05 & 0.0001 \\
\hline \multirow[t]{2}{*}{ Reduced costs } & $317 *$ & $97 \%$ & 0.05 & 0.0001 \\
\hline & $9 * *$ & $3 \%$ & 0.05 & 0.0001 \\
\hline \multirow[t]{2}{*}{ Customer satisfaction } & $315^{*}$ & $98 \%$ & 0.05 & 0.0001 \\
\hline & $8 * *$ & $2 \%$ & 0.05 & 0.0001 \\
\hline \multirow[t]{2}{*}{ Product quality } & $315^{*}$ & $98 \%$ & 0.05 & 0.0001 \\
\hline & $8 * *$ & $2 \%$ & 0.05 & 0.0001 \\
\hline \multirow[t]{2}{*}{ Organizational agility } & $328 *$ & $100 \%$ & 0.05 & 0.0001 \\
\hline & $0 * *$ & $0 \%$ & 0.05 & 0.0001 \\
\hline
\end{tabular}

*Negative assessment group; ${ }^{* *}$ Positive assessment group. 
The results of table 3 showed that more than $90 \%$ of subjects claimed that OA was less than medium in selected hospitals. Less than $5 \%$ of the subjects believed that OA was greater than medium in selected hospitals in Mazandaran province. Since significance level was less than 0.05 , the effect of those who believed that OA was less than the expected level became significant compared to those who believed that the effect was higher than expectation at $95 \%$ confidence level. As a result, null hypothesis was verified, meaning that the frequency of responses lower or equal to the expected level was verified concerning every single OA indicators. Therefore, we can conclude that competence, accountability, flexibility, speed of delivery, staff skill development, Information Technology application, integration of processes, sensitivity and accountability to market, introduction of new product, and quality of product were not optimal in selected hospitals of Mazandaran province. Therefore, OA was not optimal in selected hospitals of Mazandaran province. Kruskal-Wallis test was employed to prioritize the indicators. First, we need to determine the difference of priorities were significant or not. Kruskal-Wallis test initially uses chi-square to check the difference significance.

Table 4. Chi-Square results for hospital organizational agility.

\begin{tabular}{lcccccc}
\hline Variable/ Indicator & Number & $\begin{array}{c}\text { Calculated } \\
X^{2}\end{array}$ & df & $\begin{array}{c}\text { Critical } \\
X^{2}\end{array}$ & $\begin{array}{c}\alpha \\
\text { value }\end{array}$ \\
\hline Competence difference in hospitals & 328 & 27.916 & 16 & 26.296 & 0.05 & 0.032 \\
Accountability difference in hospitals & 328 & 17.611 & 16 & 26.296 & 0.05 & 0.347 \\
Flexibility difference in hospitals & 328 & 20.957 & 16 & 26.296 & 0.05 & 0.180 \\
Speed of delivery difference in hospitals & 328 & 12.450 & 16 & 26.296 & 0.05 & 0.712 \\
Staff skill development difference in hospitals & 328 & 24.929 & 16 & 26.296 & 0.05 & 0.071 \\
IT application difference in hospitals & 328 & 18.941 & 16 & 26.296 & 0.05 & 0.272 \\
Integration of process difference in hospitals & 328 & 19.888 & 16 & 26.296 & 0.05 & 0.225 \\
Sensitivity and accountability to market difference & 328 & 15.467 & 16 & 26.296 & 0.05 & 0.491 \\
in hospitals & & & & & & \\
Proper planning difference in hospitals & 328 & 15.467 & 16 & 26.296 & 0.05 & 0.491 \\
Introduction of new product difference in hospitals & 328 & 22.647 & 16 & 26.296 & 0.05 & 0.124 \\
Reduced cost difference in hospitals & 328 & 25.077 & 16 & 26.296 & 0.05 & 0.068 \\
Customer satisfaction difference in hospitals & 328 & 28.297 & 16 & 26.296 & 0.05 & 0.029 \\
Product quality difference in hospitals & 328 & 17.488 & 16 & 26.296 & 0.05 & 0.355 \\
Organizational agility difference in hospitals & 328 & 20.035 & 16 & 26.296 & 0.05 & 0.219 \\
Significance difference among indicators & 328 & 161.394 & 12 & 21.02 & 0.05 & 0.000 \\
\hline
\end{tabular}

Table 5. Friedman test for prioritizing indicators.

\begin{tabular}{lcc}
\hline Element & Average & Priority \\
\hline Competence & 7.03 & 5 \\
Accountability & 6.95 & 7 \\
Flexibility & 6.88 & 10 \\
Speed of Delivery & 6.52 & 12 \\
Staff Skill Development & 5.32 & 13 \\
IT Application & 7.10 & 4 \\
Integration of Processes & 6.75 & 11 \\
Sensitivity and Accountability to Market & 7.82 & 2 \\
Proper Planning & 6.95 & 8 \\
Introduction of New Products & 8.56 & 1 \\
Reduced Costs & 7.20 & 3 \\
Customer Satisfaction & 6.95 & 9 \\
Product Quality & 6.96 & 6 \\
\hline
\end{tabular}


As seen in table 4, competence had a significant difference with customer satisfaction in Mazandaran hospitals. The data showed that Azizi hospital of Juybar was the most competent, while Bou Ali Sina Hospital of Sari was the least competent. Zare Hospital of Sari showed the greatest customer satisfaction and Bou Ali Sina Hospital of Sari displayed the lowest customer satisfaction. No significant difference was found in accountability, flexibility, speed of delivery, staff skill development, Information Technology application, integration of processes, sensitivity and accountability, planning, introduction of new product, reduced costs, product quality, and OA in Mazandaran hospitals. Samen Al- A'emme Hospital of Galugah was the most agile, while Bou Ali Sina Hospital of Sari was the least agile. Table 5 shows the means core of indicators according to the priority.

The data in Table 5 showed that "introduction of new product" scored the top (8.56) and "staff skill development indicator" was the minimum (5.32) in terms of OA in hospitals.

\section{Discussion}

The results showed that competence had a significant difference in Mazandaran hospitals. The study by Yar Mohammadian et al. showed a poor condition regarding competence in Isfahan hospitals (20). The study by Bagheri Kerachi showed that competence, accountability, flexibility, and speed of change were medium to low in universities, which are consistent with the studies by Sharp (2012) $(21,22)$. The results of the study by Masih Zadeh showed that, at $99 \%$ confidence, managerial competence dimensions had a positive, significant relationship with OA (23) Competence is associated with valid and respected brand, well-known figures and experts, important projects in the past, the use of proper hardware and software tools, and strategic view among staff. According to the findings, no significant difference was found concerning accountability, flexibility, the speed of delivery, staff skill development, Information Technology application, the integration of processes, sensitivity and accountability to markets, the proper planning, introduction of new product, the cost reduction, patient satisfaction, the product quality, and OA in Mazandaran hospitals. The study by Bagherzadeh et al. showed that a gap existed between the status quo and optimal condition in post office concerning accountability and post office did not have optimal flexibility (24). Ghasemi, in his thesis, rated improper accountability and flexibility (25). In today's competitive market, organizational accountability development and improvement is felt. Agile paradigm-based strategic thinking is one of the ways of accountability to environmental dynamism and leadership in an organization. In order to survive and progress in unreliable and varying environment, organizations need to be organized in a way that they have flexible and innovative organizational structure. This enables them to promote fast decision making. An agile organization is able to provide new services faster. Solving the problem of each customer is a goal. This way, agile organizations promote the quality of customer experience. As a result, they are able to retain their customers and attract new ones.

Ribeiro and Colombo concluded that smart and multi-skill staff had a significant impact on the agility of operational sector (26). Therefore, non-skilled and knowledgeable human resources would be disadvantageous even if they tried hard. The study by Lin et al showed that the speed of information analysis was the most effective and capability of process survival was the least effective factor in determining agility (27). Agility is conceptualized as a dynamic capability. As a result, organizations obtain competitive advantage by applying information technology.

The study by Vaezi and Sedaghat Pour showed that organizational learning processes need to be taken into account and 
efforts must be made by providing essential educational infrastructures in order to obtain knowledge (28). In a research by Zang et al., the stroke registry and the timely and cost-effective tools of analysis report have been provided in the analysis of agile health through the flexible leveraging and participatory scale of information management (29). In today's competitive business environment, organizations cannot survive by relying on constant processes because although processes were initially designed well, they need revision in order to maintain the competitive advantage. Van Hook, Harrison and Christopher believed that agility is a focus on management of accountability to dynamic markets and customer demands. They stated that agility had a significant relationship with sensitivity and accountability (30). All elements in supply chain need to move along a unique goal so that the difference does not lower the process of accountability to customers. In a study by Younesian, turn the hospitals into a perceptible environment using up-to-date tablet technology (31). Long-term planning is essential in Iranian banks for customer satisfaction based on automation system development in order to facilitate the banking affairs (32). A dynamic, applied, and holistic plan is required for organizational modifications. The plan must contain the modification objectives (meeting the needs and society's expectations). Such plan must also be capable of continuous and basic change in organizations in accordance with the goals. The study by Suresh and Patri showed that an agile organization is evaluated by the realization of customer needs and preparation for the introduction of new products (33). Alzobi et al. found that new product development process had a significant relationship with agility (34). Fast, new product development process enables the manufacturers to reach the optimal profitability by new innovations, the adaption with customers' needs, and keeping pace with other firms.
The study by Molla Husseini and Mostafavi showed that an agile organization can reduce manufacturing costs and increase market share (35). State organizations need agility more than private ones due to frequent number of customers, the need to meet the demands, and in line with excellence concerning speed, quality, and more importantly, reduced costs. In their research, McAullay et al. stated that the Australian Ministry of Health and Aging, used data mining tools to extract further side effects of drugs in order to meet the needs and satisfaction of the patients (36). The study by Abdi Talarposhti et al showed that increasing productivity, and staff and customer satisfaction were the most important OA advantages (37). Patient satisfaction is a human experience mentally evaluated by individuals based on compatibility between the received care and expectations. The study by Laanti et al. showed that the advantages of using agility techniques are higher satisfaction, increased quality, and transparency in Nokia Company (38). In his study, Karami stated that, in addition to discovering new medical knowledge, it is possible to find information on trends, patterns, and therapeutic outcomes using data mining and textual analytics tools in the organization in order to improve the quality of cares (39). Specialists at the Spinal Disorders Hospital in Los Angeles have used data mining to discover the various factors that contribute to the success or failure of spinal surgery and improve cares (40). In agility section if health care, quality is of great importance because it is responsible for the health care and the life of community. In his research entitled "Model- driven ontology for agility engineering in the US healthcare system", Ramados stated that a framework and methodology called the Ontology-Based Health Systems Engineering Model" was used to monitor and control health systems (41). In the study by Kitsmiller et al., the value of communication and agility control is an advantage, which changes the simplification of the natural evolution of a 
consistent implementation process. This comparison shows that an agile approach increases traditional implementation techniques to meet the demands of today's complicated healthcare environment (42). The study by Fathian et al. showed that the mean agility was moderate to low in Mega Motor Co. which is consistent with our study (43). Therefore, the need for agility in the hospitals is necessary. But on the other hand, the development of a framework for agile organizations has faced challenges. Since the achievement of the specific goals of an organization depends on its type, the organization can determine some areas for agility, and try to get agility in those areas. Some of the limitations of this research are the novelty of the subject of agility for managers, the lack of cooperation of some experts because of being busy, and the subjectivity of responses due to the use of only one questionnaire. The questionnaires were filled out after providing necessary explanations in these regards to the participants.

\section{References}

1. Yang J. Supply chain agility: securing performance for Chinese Manufacturers. Int J Prod Econ. 2014; 150(C): 104-13. doi:10.1016/j.ijpe.2013.12.018.

2. Dahmardeh N, Banihashemi SA. Organizational agility and agile manufacturing. Euro Journals, Inc. 2010; 27: 178-84. ISSN 1450-2275 Issue 27 (2010).

3. Pan F, Nagi P. Multi-echelon supply chain network design in agile manufacturing. Omega. 2013; 41(6): 969-83. doi:10.1016/j.omega.2012.12.004.

4. Zain M, Rose RC, Abdullah I, Masrom M. The relationship between information technology acceptance and organizational agility in Malaysia. Info Manag. 2005; 42(6):829-39. doi.org/10.1016/j.im.2004.09.001.

\section{Conclusion}

According to the results of this study, the introduction of the new products gained the highest and the indicator of staff skills development gained the lowest score in terms of OA in the hospitals. Whereas it is necessary for the authorities and planners in the field of agility of the hospitals to know the factors influencing agility; it is recommended to plan for customer satisfaction, timely utilization of facilities, reduction of the lost costs, as well as the empowerment of individuals to work in teams.

\section{Acknowledgments}

This article has been implemented with the code with project code 8679-5 and supported by Islamic Azad University of Sari Branch.

5. Agarwal A, Shankar R, Tiwari MK. Modeling agility of supply chain. Indus Market Manag.2007; 36(4):443-57. doi.org/10.1016/jindmarman.2005.12.0 04.

6. Tsai Y. Relationship between organizational culture, leadership behavior and job satisfaction. BMC Health Serv Res. 2011; 11: 98. doi: 10.1186/1472-6963-11-98.

7. Chen H, Fuller SS, Friedman C, Hersh W. Medical informatics: knowledge management and data mining in biomedicine. New York: Springer Science and Business Media; 2006.

8. Popowich F. Using text mining and natural language processing for health care claims processing. ACM SIGKDD Explorations Newsletter. 2005; 7(1): 59-66. doi:10.1145/1089815.1089824. 
9. Hamidieh A, Mirzazadeh A. Prioritizing the performance evaluation indicators of the academic e-learning system using fuzzy approach. Ind J Sci Technol. 2015; 8 (28):1-11. doi: 10.17485/ijst/2015/v8i28/71900.

10. Senkubuge F, Modisenyane M, Bishaw T. Strengthening health systems by health sector reforms. Glob Health Act. 2014; 7 : 23568-69. doi: 10.3402/gha.v7.23568.

11. Lotfi F, Bastani P, Hadian M, Hamidi $\mathrm{H}$, Nouraei Motlagh S, Delavari S. prowess. [Evaluating the performance of hospitals affiliated with Iran University of medical sciences: the use of economic techniques in the field of health]. Manag Slamt J. 2015; 18 (59): 43-54. (Persian)

12. Griffin D. Translation: Arab M, Ravangard R, Vali L, Kavosi Z. Hospitals: What They Are and How they Work? Tehran. 2012.

13. Yauch CA. Measuring agility as a performance outcome. J Manufactur Technol Manag. 2011; 22(3):384-404. doi.org/10.1108/17410381111112738.

14. Zariei Gavgani F, PourReza A, Hosseini M, Akbari F. [The views of senior managers of private hospitals in Tehran about the problems of private hospitals]. Payesh J. 2010; 10(1): 7381. (Persian)

15. Wyatt JC, Sullivan F. What is health information? BMJ. 2005; 331 (7516): 566-68.

doi: 10.1136/bmj.331.7516.566

16. Hotho A, Nürnberger A, Paaß G. A brief survey of text mining. LDVForum 20 (2005), No.1, pp.19-62.

17. Karami M, Rahimi A, Shahmirzadi A H. Clinical data warehouse: an effective tool to create intelligence in disease management. Health Care Manag. 2017;36(4):380-84. doi: 10.1097/HCM.0000000000000113

18. Yusuf YY, Gunasekaran A, Musa A, Dauda M, El-Berishy NM, Cang S. A Relational study of supply chain agility, competitiveness and business performance in the oil and gas industry. Int J Prod Econ. 2014; 147:531-43.doi: 10.1016/j.ijpe.2012.10.009.

19. Belay H, Azim T, Kassahun H. Assessment of health management information system (HMIS) performance in SNNPR, Ethiopia.2014.

20. Yarmohammadian MH, Samooie R, Khodayari ZR, Ayoobian A, Bagherian MH. Agility in Isfahan hospitals, Iran. Health Info Manag. 2012; 8 (8):11228. (Persian)

21. Bagheri Kerachi A, Abbaspour A. Adaptation rate of universities with agile organization indices in the viewpoint of faculty members. Educ Strategy Med Sci. 2014; 7 (4):207-14. (Persian)

22. Levitt DS, Hauer KE, Poncelet A, Mookherjee S. An innovative quality improvement curriculum for third-year medical students. Med Educ Online. 2012; $17 . \quad$ doi: 10.3402/meo.v17i0.18391.

23. Treiger TM1, Fink-Samnick E. COLLABORATE@, Part IV: Ramping Up Competency-Based Performance Management. Prof Case Manag. 2017;22(3):101-115. doi: 10.1097/NCM.0000000000000217.

24. Bagherzadeh MR, Baloui JA, Moafi Madani SR. [Investigating the status of agility capabilities in government organizations (Case Study of Mazandaran Post Office)]. J Industr Strateg Manag. 2010; 7(18):37-49. (Persian)

25. Qasimi Sh. Identification and analysis of factors affecting the staff's agility of the national bank of Sanandaj. Int J Human Cultur Stud. 2016; (Special Issue):1445-58.

26. Ribeiro L, Barata J, Colombo A. Supporting agile supply chain using a service-oriented shop floor. Eng Appl Artif Intell. 2009; 22(6):950-60. doi:10.1016/j.engappai.2008.10.023

27. Lin CT, Chiu H, Tseng YH. Agility evaluation using fuzzy logic. Int $\mathbf{J}$ 
Produc Econom. 2006; 101:353-68. www.elsevier.com/locate/ijpe

28. Vaezi R, Sedaghatpour F. Egovernment and organization agility (Research in Civil Registration Organization of Tehran Province). J Med Sci. 2012; 22(67): 1-17. (Persian)

29. Zeng J, Jumbo A, Zhang J. embracing agile health analytics: a use case for stroke registry. Int J Health Res Innov. 2014; 2(2): 1-10.

30. Van Hoek R, Harrison A, Christopher M. Measuring agile capabilities in the supply chain. Int $\mathbf{J}$ Operat Produc Manag. 2001; 21(1/2): 126-48. doi: $10.1108 / 01443570110358495$.

31. Sonia M, Khoorasgani G. The impact of cloud computing technology on organizational performance; financial, customer, operational (Case Study: Zarin Iran Porcelain Industries Co.). Mediter J Soc Sci.2016; 7(4):279-88. doi:10.5901/mjss.2016.v7n4s1p279

32. Najafbaigi R. Banking automation in iran, its social and banking effects. J Perform Manag. 2010; 23(1):11-22. (Persian)

33. Suresh M, Patri R. Agility Assessment Using Fuzzy Logic Approach: a Case of Healthcare dispensary. BMC Health Serv Res. 2017; 17(1): 394. doi: 10.1186/s12913-017-2332-y.

34. Alzoubi AE, Al-Otoum FJ, Albatainh AK. Factors associated affecting organization agility on product development. IJRRAS.2011; 9(3): 50316.

35. Molla Hosseini A, Mostafavi S. [Organizational agility assessment using fuzzy logic]. Tadbir. 2007; 186: 3-5. (Persian)
36. McAullay D, Williams G, Chen J, Jin $\mathrm{H}$, Proceed He H, Sparks R, et al. A delivery framework for health data mining and analytics. Austr Comput Soc. 2005; 38:381-87.

37. Abdi Talarposhti M, Mahmodi G, Jahani MA. [Factors affecting supply chain agility at hospitals in Iran. $\mathbf{J}$ Health Admin]. 2016; 19(64): 7-18. (Persian)

38. Laanti M, Salo O, Abrahamsoon P. Agile methods rapidly replacing traditional methods at Nokia: a survey of opinions on agile transformation. Inf Softw Technol. 2011; (53): 276-90. doi:10.1016/J.Infsof.2010.11.010.

39. Karami M. [Application of data-mining and text-mining analyzer tools in agility on healthcare organizations]. J Health Admin. 2007; 10(30):15-9. (Persian)

40. Prather JC, Lobach DF, Goodwin LK, Hales JW, Hage ML Hommond WE. Medical data mining: knowledge discovery in a clinical data warehouse. Proc AMIA Annu Fall Symp. 1997:101-5.

41. Ramadas K. Agile banking - managing the challenge of change. Finance from Infosys; 2014. P.54.

42. Kitzmiller R, Hunt E, Sproat SB. Adopting best practices:"agility" moves from software development to healthcare project management. Comput Inform Nurs. 2006; 24(2): 7582.

43. Fathian M, Golchinpour M, Khosroshahi S. [Organizational agility: a case study on MegaMotors]. Tadbir. 2006; 17(175):37-43. (Persian) 